\title{
A ENTEXTUALIZAÇÃO NA CO- PRODUÇÃO DOS DISCURSOS LEGAIS ENVOLVIDOS NAS HISTÓRIAS DE MULHERES INFRATORAS QUE PLEITEIAM A PRISÃO DOMICILIAR EM LUGAR DA PRISÃO PREVENTIVA
}

\author{
Deise Ferreira Viana de CASTRO (DD \\ Pontifícia Universidade Católica do Rio de Janeiro (PUC-Rio)
}

\section{ช}

OPEN ACCESS

EDITADO POR

- Miguel Oliveira, Jr. (UFAL)

- René Almeida (UFS)

REVISADO POR

- Dalexon Silva (ULisboa)

- Nome Sobrenome (PUC-SP)

DATAS

- Recebido: 26/01/2020

- Aceito: 25/06/2020

- Publicado: 02/09/2020

\section{COMO CITAR}

CASTRO, Deise F. V. (2020). A entextualização na co-construção dos discursos legais envolvidos nas histórias de mulheres infratoras que pleiteiam a prisão domiciliar em lugar da prisão preventiva. Cadernos de Linguística, v. 1, n. 2, p. 01-23.

\section{RESUMO}

Neste trabalho, analisamos o discurso empregado em um processo judicial envolvendo duas mulheres infratoras grávidas presas, uma que conseguiu o benefício da prisão domiciliar por meio do Artigo 318 da lei 3689/41 do Código de Processo Penal (CPP) e outra não. Buscamos apresentar, em uma perspectiva etnometodológica do texto, de que forma a entextualização está ligada à co-producão de textos, suas trajetórias e aos contextos de processos que envolvam tal situação e os recortes possíveis na análise discursiva como prática social e aplicada à linguagem jurídico-institucional. Procuramos pesquisar de que forma os discursos são co-construídos pelas rés e pelos profissionais da área, interpretados, retextualizados e entextualizados até a sentença. Buscamos investigar os discursos escritos e a forma como são organizados incorporando aspectos do contexto (BLOOMAERT, 2001 e 2005) de forma que o texto resultante carregue em si elementos da história narrada inicialmente, assim como elementos que apresentem a trajetória dos textos (BLOOMAERT, 2001; CARRANZA, 2010) e das narrativas co-produzidas pelos profissionais envolvidos em relação ao que foi dito pelas rés no início e retextualizado, recontextualizado até o final do processo (ERLICH, 2007 e 2015). Os dados foram gerados a partir do pedido de prisão domiciliar feito pelo 
Defensor Público de cada uma das mulheres e da sentença proferida pelo juiz responsável por cada caso. Observamos que as entextualizações do delito, mesmo sendo o mesmo, são feitas de formas diferentes pelos juízes, bem como das leis que regem a concessão dessa pena alternativa para mulheres infratoras, influenciando diretamente as sentenças.

\section{ABSTRACT}

In this paper, we analyze the discourse used in a judicial process involving two imprisoned pregnant offenders, one who obtained the benefit of house arrest through Article 318 of Law 3689/41 of the Brazilian Criminal Procedure Code (CPP) and another one who did not. We seek to present, in an ethnomethodological perspective of the text, how entextualization is linked to the co-production of texts, their trajectories and the contexts of processes that involve such situation and the possible perspectives in the discursive analysis as social practice and applied to the institutional legal language. Thus, we seek to examine how the discourses are co-constructed by the defendants and legal professionals, interpreted, retextualized and entextualized until the sentence. We investigate written discourses and the way they are organized by incorporating aspects of the context (BLOOMAERT, 2001 and 2005) in such a way that the resulting text carries elements of the story initially narrated, as well as elements that present the trajectory of the texts (BLOOMAERT, 2001; CARRANZA, 2010) and the narratives co-produced by the professionals involved in relation to what was said by the defendants at the beginning and retextualized, recontextualized until the end of the process (ERLICH, 2007 e 2015). Data was generated from the request for house arrest made by the Public Defender of each of the women and the sentence given by the judge responsible for each case. We note that the entextualizations of the crime, even though it is same, are made in different ways by the judges as well as of the laws that grant this alternative penalty for women offenders. This directly influences the sentence.

\section{PALAVRAS-CHAVE}

Análise Sociointeracionista do Discurso; Entextualização; Trajetórias Textuais; Discurso Jurídico.

\section{KEYWORDS}

Social-Interactional Discourse Analysis; Entextualization; Textual Trajectories; Legal Discourse. 


\section{INTRODUÇÃO}

Em março de 2017, meios de comunicação digitais e impressos divulgaram amplamente a prisão domiciliar da ex-primeira-dama do Estado do Rio de Janeiro, Adriana Ancelmo, que havia sido presa em dezembro de 2016 pela Operação Calicute, um desdobramento da Operação Lava-Jato. Ela estava presa preventivamente por corrupção passiva e lavagem de dinheiro, conforme preveem as leis brasileiras, no Complexo Penitenciário de Bangu, no Rio de Janeiro, e teve o pedido de prisão domiciliar feito pelos advogados de defesa e acoIhido pelo STJ conforme observamos a seguir

O Superior Tribunal de Justiça (STJ) acolheu, nesta sexta-feira (24), recurso da defesa da advogada Adriana Ancelmo, mulher do ex-governador Sérgio Cabral, e manteve a decisão da Justiça Federal no Rio que concedia a ela prisão domiciliar. De acordo com o órgão, a concessão da liminar será publicada na terça-feira (28). (G1, Rio de Janeiro, 2017)

Contudo, o caso da ex-primeira-dama teve desdobramentos inesperados e, muitas vezes, controversos, como veremos mais adiante. A defesa de Adriana se baseou no Artigo 318 do Decreto-Lei 3689/41 do Código de Processo Penal (CPP) que teve alterações recentes, conforme se observa a seguir, e prevê, entre outros incisos,

Art. 318. Poderá o juiz substituir a prisão preventiva pela domiciliar quando o agente for: (Redação dada pela Lei $n^{\circ} 12.403$, de 2011).

[...]

IV - gestante; (Redação dada pela Lei n ${ }^{\circ} 13.257$, de 2016)

$\mathrm{V}$ - mulher com filho de até 12 (doze) anos de idade incompletos; (Incluído pela Lei ${ }^{\circ} 13.257$. de 2016)

VI - homem, caso seja o único responsável pelos cuidados do filho de até 12 (doze) anos de idade incompletos. (Incluído pela Lei $n^{\circ} 13.257$, de 2016) [...] (Lei 3689/41)

Desta forma, a prisão domiciliar foi concedida em caráter substitutivo à prisão preventiva, visto que o juiz responsável pelo caso entendeu que os filhos da ré em questão (de 11 e 14 anos à época) não deveriam ser privados do convívio com a mãe, já que o pai (o ex-governador Sérgio Cabral) também está preso. Entretanto, o caso trouxe discussões e reflexões a respeito da aplicabilidade da lei, suas interpretações e seus desdobramentos. Quantas mulheres conseguem ser beneficiadas pela lei? Quem são elas? Adriana Ancelmo teria conseguido o benefício devido às suas condições sócio-históricas: classe alta, branca, muIher de um ex-governador? Como são construídos e redigidos os processos judiciais envolvendo essas mulheres?

Essas foram questões bastante discutidas à época tendo em vista a raridade da aplicação da lei. O Brasil é signatário das Regras de Bangkok¹, um acordo firmado com a

1 Regras de Bangkok - Regras das Nações Unidas para o tratamento de mulheres presas e medidas não privativas de liberdade para mulheres infratoras - criadas devido ao aumento da população carcerária feminina não só no Brasil, mas também em outros países. 
Organização das Nações Unidas (ONU) no ano de 2010, que estabelece regras para o tratamento de mulheres presas e medidas não privativas de liberdade para mulheres infratoras tendo em vista o contato com os filhos que estejam na primeira infância e no início da adolescência, mas essa prática ainda é limitada no país. De acordo com Arlanza Rebello, coordenadora do Núcleo de Defesa dos Direitos da Mulher (Nudem), da Defensoria Pública do Rio de Janeiro, em entrevista ao jornal Gazeta do Povo,

\footnotetext{
O questionamento em torno da liberdade dela [Adriana Ancelmo] é pertinente porque o nosso sistema é muito seletivo. O fato de ser uma mulher muito conhecida traz, de certa maneira, esse olhar muito assimétrico do nosso sistema de defesa. No Brasil, quem está presa são mulheres pobres e negras. (Neitsch, 2017)
}

E assim surgiu a motivação para este trabalho. Os fatos narrados no caso em questão, as condições sociais e econômicas da ex-primeira-dama, as interpretações da lei e o seu (des)cumprimento suscitaram o interesse em pesquisar como são tratados os casos previstos nos incisos IV e V do Artigo 318 do CPP em relação às mulheres presas que poderiam também ser beneficiadas.

Na esteira do caso Adriana Ancelmo, em fevereiro de 2018, a $2^{\text {a }}$ Turma do Supremo Tribunal Federal (STF), em julgamento histórico, ao examinar e decidir o Habeas Corpus (HC) 143.641, impetrado pelo Coletivo de Advogados de Direitos Humanos (Cadhu) e pela Defensoria Pública da União, bem como pelo defensor público-geral federal, resolveu estender a todas as mulheres infratoras grávidas ou com filhos menores de 12 anos o direito à prisão domiciliar em lugar da prisão cautelar. Consta no documento que

\footnotetext{
Diante dessas soluções díspares, e para evitar tanto a arbitrariedade judicial quanto a sistemática supressão de direitos, típica de sistemas jurídicos que não dispõem de soluções coletivas para problemas estruturais, a melhor saída, a meu ver, no feito sob exame, consiste em conceder a ordem, estabelecendo parâmetros a serem observados, sem maiores dificuldades, pelos juízes, quando se depararem com a possibilidade de substituir a prisão preventiva pela domiciliar. (HC 142641/SP, p. 32
}

Em princípio, isso nos faz pensar que todas que se encontram nessa situação serão beneficiadas pelo Habeas Corpus, mas não foi o que se observou nos processos consultados para esta pesquisa como veremos posteriormente.

Os dados que serão apresentados neste trabalho fazem parte da pesquisa para a tese de doutoramento da autora (em andamento) e referem-se a um mesmo processo envolvendo duas mulheres infratoras. Uma delas foi beneficiada com a prisão domiciliar por estar grávida, mas a outra não, mesmo estando nas mesmas condições. As duas foram representadas por Defensor Público, tiveram seus julgamentos feitos por juízes diferentes que deram suas sentenças de forma diferente mesmo existindo a legislação comentada anteriormente.

Desta forma, temos como objetivos analisar (I) como os pedidos de prisão domiciliar são feitos; (II) de que forma são julgados por meio das sentenças proferidas pelo juiz/ 
desembargador responsável pelo caso e (III) como a legislação em vigor é utilizada pelos profissionais envolvidos.

Para isso, utilizamos o conceito de entextualização, termo cunhado por Bauman e Briggs (1990), que engloba o processo de tornar o discurso passível de extração de seu cenário interacional. Isso porque a entextualização captura os sentidos da relativa autonomia das unidades linguísticas de se tornarem textos, no trânsito de um contexto a outro (BRIGGS, 2007; SILVA, 2014). Na presente pesquisa, como o acesso será apenas aos textos que compõem o pedido de Habeas Corpus, ${ }^{2}$ da Sentença Judicial e do Acórdão ${ }^{3}$ que autoriza ou denega a ordem de prisão domiciliar, buscaremos analisar os discursos escritos e a forma como são organizados incorporando aspectos do contexto (BLOOMAERT, 2001 e 2005) de tal forma que o texto resultante carregue em si elementos da história narrada inicialmente, assim como elementos que apresentem a trajetória dos textos (BLOOMAERT, 2001; CARRANZA, 2010; WORTHAM e RHODES, 2015) e das narrativas co-produzidas pelos profissionais envolvidos em relação ao que foi dito pelas rés no início e retextualizado, recontextualizado até o final do processo (ERLICH, 2007 e 2015).

Embora existam diversas abordagens de estudos de texto, o objetivo, aqui, é refletir sobre as transformações que os textos jurídicos apresentam no decorrer de um processo judicial, já que a história registrada inicialmente no Boletim de Ocorrência em uma delegacia "viaja" pelo processo até a sentença final. Como diz Silva,

\begin{abstract}
A relativa autonomia dos textos não significa que o texto deva ser analisado como objeto autônomo. Embora a análise do texto como um objeto em si seja legítima para determinados propósitos, para muitos outros propósitos entender um texto como "autossuficiente" é congelar sua historicidade; essa postura pode, em último caso, nos impedir de entender como certos elementos textuais se tornaram "verdade", "mentira", "voz", "fato", "afeto" a partir de determinados regimes de circulação de discursos (SILVA, 2014, p. 68).
\end{abstract}

Tomando como base o contexto institucional jurídico, a circulação dos discursos envolve diversos profissionais nas mais diversas fases do processo judicial, por isso buscaremos entender como os textos produzidos são entextualizados nos documentos que compõem o processo, pois, embora haja uma certa autonomia entre eles, é necessário entender o contexto do processo como um todo. Assim, a entextualização, como veremos a seguir, vai além da retextualização ou transformação um texto em outro (MARCURSCHI, 2004), seja da oralidade para a escrita ou da escrita para a escrita, e se diferencia de outras

2 Habeas corpus é uma medida jurídica para proteger indivíduos que estão tendo sua liberdade infringida, é um direito do cidadão, e está na Constituição brasileira.

3 Acórdão um acórdão judicial trata-se de decisão proferida por membros colegiados de um tribunal de segunda instância, como os Tribunais Regionais Federais (TRFs), ou por tribunais superiores, Tribunal Superior do Trabalho (TST), por exemplo, por juízes, ministros ou desembargadores. A principal diferença entre acórdão e sentença é que o primeiro é emitido por uma instância superior, por um grupo colegiado, normalmente composto por três juízes, desembargadores ou ministros. Já a sentença e até mesmo uma decisão interlocutória, são emitidas por autoridade única, um juiz ou um desembargador, por exemplo, em primeira instância. 
formas de textualização, visto que demonstra a capacidade de um texto referenciar o outro abordando aspectos do contexto jurídico no qual está inserido.

Uma análise puramente textual não abrangeria toda a complexidade dos contextos observados. Andrus (2011), Bloomaert (2001), Erlich, (2015) e outros autores que serão apresentados posteriormente versam sobre a importância de se estudarem textos e contextos por serem co-construídos continuamente como parte da interação. Desta forma, tomamos o texto como forma de interação e diálogo, como postula Bahktin (2003), já que o enunciado não é completo em si mesmo e traz consigo marcas de outros enunciados e oferece respostas a outros que fazem parte da cadeia dialógica do texto, que vai além da intertextualidade. É sobre essa movimentação observada na construção textual como ação social que este trabalho se debruça.

Algumas noções sobre análise de narrativas também serão abordadas tendo em vista os aspectos situados e relacionais (dialógicos) da ação conjunta de narrar pelos atores sociais envolvidos na composição do processo judicial, já que a natureza da ação discursiva de narrar é sempre orientada a plateias e situações sociais distintas e fazem parte de acordos institucionais distintos (BASTOS e BIAR, 2015).

Nas palavras de Moita Lopes (2006, p 23), "são necessárias teorizações que dialoguem com o mundo contemporâneo, com as práticas sociais que as pessoas vivem, como também desenhos de pesquisa que considerem diretamente os interesses daqueles que trabaIham, agem etc. no contexto de aplicação". Assim, a metodologia desta pesquisa terá uma abordagem de natureza qualitativa e interpretativista (MOITA LOPES, 1994; DENZIN e LINCOLN, 2006) a fim de se debruçar sobre a importância dos registros das narrativas em contextos jurídicos de mulheres infratoras/criminosas, de suas interpretações e das possíveis consequências que podem gerar.

Portanto, tomando como foco as considerações acima, apresentaremos, inicialmente, a fundamentação teórica utilizada e sua relevância para esta pesquisa. Em seguida, as etapas metodológicas e os procedimentos adotados na geração dos dados a serem analisados. Na seção posterior, a análise de dados será feita com interpretações e reflexões sobre as descobertas trazidas pelos dados coletados. E, por último, teceremos algumas considerações finais sobre a pesquisa e seus possíveis encaminhamentos.

\section{A ANÁLISE DE NARRATIVAS NOS ESTUDOS DO DISCURSO E DA INTERAÇÃO SOCIAL}

Narrativas fazem parte da vida cotidiana de todos os indivíduos, não apenas quando estão presentes nos textos literários, jornalísticos, ficcionais e outros tipos de textos, mas também quando contamos a nossa história pessoal, seja por meio de curtos ou longos 
episódios. Bastos e Biar (2015, p. 99), trazem a narrativa conceituada como "o discurso construído na ação de se contar histórias em contextos cotidianos ou institucionais, em situações ditas espontâneas ou em situação de entrevista para pesquisa social". Nas últimas décadas, os estudos sobre narrativas têm se mostrado produtivos nas ciências sociais. Conforme postula Freeman (2015),

\footnotetext{
a narrativa pode ser, e geralmente é, um método, um modo de investigação do ser humano. Além disso, a ideia de narrativa pode ser empregada no contexto da teoria sobre algum aspecto da condição humana, por exemplo, cognição ou identidade pessoal. Finalmente, pode ser considerado no contexto da prática, ou seja, os vários "feitos" humanos que fazem parte da vida cotidiana (Freeman, 2015, p. 22, grifos mantidos do original).
}

Desta forma, os indivíduos organizam suas experiências de vida e constroem sentidos sobre si mesmos ao relatarem suas histórias (BASTOS E BIAR, 2015). Partindo de estudos mais recentes sobre Análise da Narrativa, os pesquisadores debatem a teoria clássica de Labov (1972) sobre a estrutura do ato de narrar e apresentam algumas críticas, revisões e contribuições para os estudos desse tipo de análise como uma prática para os estudos de análise do discurso sociointeracionista (BASTOS, 2005; DE FINA e GEORGAKOPOULOU, 2008; BASTOS E BIAR, 2015). A narrativa é considerada, então, uma construção social e não somente como uma representação do que aconteceu (BASTOS, 2004). Esse tipo de análise pode ajudar a compreender como os indivíduos, na interação com os outros, co-constroem tanto suas identidades quanto a ordem social que os cerca (BASTOS, 2005).

Tendo em vista os objetivos deste trabalho e as interações sociais co-construídas ao se registrarem os mais diversos tipos de documentos jurídicos, a análise da narrativa contribui para os estudos da linguagem nesse contexto. Como expõem Bastos e Biar (2015), esta ferramenta: "(I) promove diálogo entre múltiplas áreas do saber; (II) se debruça sobre a fala dos mais diversos atores sociais, nos mais diversos contextos; (III) reverbera entendimento do discurso narrativo como prática social construtiva da realidade; (...)".

É com essa perspectiva social do discurso que este trabalho se identifica. Como postula Goffman (2002), ela proporciona possibilidades múltiplas de entendimento da linguagem por meio de regras culturais e de convivência dos indivíduos que organizam socialmente o comportamento daqueles presentes à situação. As interações presentes no decorrer de um processo judicial nos convidam a olhar a situação social como cenário para a pesquisa. A noção de discurso aqui utilizada decorre dessa abordagem social e interacional, tendo em vista o entendimento de como os discursos se co-constroem ao longo do processo. Sob a perspectiva teórica de Fairclough (2001), discurso é uma forma de prática social, modo de ação sobre o mundo e a sociedade, um elemento da vida social interconectado a outros elementos. O autor também o define como "um modo de ação, uma forma como as pessoas podem agir sobre o mundo e especialmente sobre os outros, como também uma representação" (Fairclough, 2001, p. 91). Gee (2005), por sua vez, versa a respeito dos Discursos (no plural e com D maiúsculo) construídos socialmente "como formas de 
integrar linguagem, ações, interações, formas de pensar, acreditar, valorizar, usar diversos símbolos, ferramentas e objetos para representar um determinado tipo de identidade socialmente reconhecível” (Gee, 2005 p. 21).

De Fina e Georgakopoulou (2008) propõem a abordagem sociointeracionista para os estudos das narrativas, já que a análise da interação é fundamental nesse tipo de estudo e a investigação das estreitas relações dos processos interacionais do ato de narrar com processos sociais mais amplos se configura como um pré-requisito para a pesquisa de cunho social. Por isso, o modelo laboviano se mostra insuficiente para tratar de experiências contadas em determinados contextos que surgem a partir da interação. E aqui, é necessário observar também como ocorre a co-construção da atividade discursiva entre falante/ ouvinte (ré/ profissional jurídico), já que os papéis exercidos por cada um deles são bastante diferentes. O receptor da história não é totalmente passivo, pois pode rejeitar, modificar ou prejudicar pontos importantes dos relatos e das narrativas4 (DE FINA; GEORGAKOPOULOU, 2008).

A ideia de que as narrativas fazem parte de práticas sociais nos leva a considerar contextos diversificados nos quais é necessário detalhar as atividades sociais e discursivas. Pretendemos investigar como acontece a organização dos discursos e as mensagens que orientam a conduta dos participantes e atribuem significado à atividade em desenvolvimento nas situações institucionais mencionadas anteriormente e que constituirão os textos a serem analisados como dados da pesquisa.

No âmbito deste trabalho, faz-se necessário estudá-las já que os falantes se constroem pela linguagem ao contarem sua versão dos fatos na delegacia e em outras oportunidades que possam ter para se expressar no decorrer do processo jurídico. Mais especificamente, busca-se analisar como tais narrativas são tratadas nos documentos que dão continuidade ao caso e se o contexto institucional, por meio de possíveis padronizações e diferentes abordagens dos profissionais envolvidos, exerce influência nas tratativas do caso, no julgamento e no veredito final.

\section{ENTEXTUALIZACÕES, (CON)TEXTO JURÍDICO E TRAJETÓRIAS TEXTUAIS}

Contextos profissionais envolvem diferentes perspectivas, diferentes conhecimentos profissionais e diferentes abordagens ideológicas, culturais e especificas das profissões para 
o mesmo fenômeno textual. Além disso, a reprodução de textos envolve transformações de forma, contexto e significado que inviabilizam a réplica exata (BRIGGS, 2007).

É necessário analisar como os participantes levam em consideração as questões sobre quem fala para quem, como fala, sobre o que fala, em que lugar e em que momento. Mais ainda, como o discurso registrado a partir de tais interações deve ser observado tendo em vista os contextos de produção. É necessário estudar o texto por meio de uma abordagem social sem desconsiderar as características próprias das práticas situadas dos grupos sociais (SILVA, 2014).

Assim, a análise centrada no discurso defende que uma ampla gama de características formais pode sinalizar a força ilocucionária ${ }^{5}$ das enunciações, a qual emerge não somente de sua localização dentro do gênero e lugar social em particular, mas também das relações entre a performance e outros eventos de fala que a precedem e sucedem (BAUMAN e BRIGGS, 1990). Os gêneros dão forma e são formados por gênero, classe social, etnicidade, idade tempo, espaço e outros fatores, daí a relevância dos estudos sobre as relações entre gênero textual e força ilocucionária na produção dos discursos. Esta última, de acordo com os autores, "pode ser comunicada por uma série de elementos do micro ao macro e, mais importante, pela interação entre esses elementos" (BAUMAN e BRIGGS, 1990: 194). A performance, por sua vez, oferece um enquadre que convida à reflexão crítica sobre os processos comunicativos e pode ser observada por meio dos textos.

Bauman e Briggs, no mesmo artigo, dão vida ao termo entextualização como "o processo de tornar o discurso passível de extração, de transformar um trecho de produção linguística em uma unidade - um texto - que pode ser extraído de seu cenário interacional" (BAUMAN e BRIGGS, 1990: 206). A entextualização incorpora aspectos do contexto de forma que o texto resultante contenha elementos da história e de seu uso. É a capacidade do texto de referir-se a si mesmo.

Briggs (2007) postula ainda que o discurso pode ser considerado não como restrito a um único e limitado contexto, mas como continuamente descontextualizado e recontextualizado - extraído de determinados textos, gêneros, contextos e mundos sociais e inseridos em outros. De acordo com esta visão, o poder reside não somente no controle da forma como o discurso se revela no contexto de sua produção, mas na obtenção de controle sobre a recontextualização - moldando seu desenho em outros discursos e contextos e quando, onde, como e por quem será usado posteriormente. A reprodução de textos envolve transformações de forma, contexto e significado que inviabilizam a réplica exata. As práticas de entextualização se tornam efeitos de transformação. Isso vem corroborar o que se observa

5 Seguindo o pensamento de Austin (1990) e Koch (2003), a força ilocucionária está ligada não somente ao que é dito, mas também às intenções do falante que estão presentes naquilo que é dito. Isso diz respeito aos diferentes usos e significados das sentenças em determinados contextos, fazendo referência à Teoria dos Atos e Fala de Austin que envolve atos locucionários, ilocucionários e perlocucionários. 
na construção dos textos de um processo jurídico pelos autores/ atores sociais envolvidos. Erlich (2015) complementa esse pensamento no que tange aos participantes do sistema legal. Já que os profissionais podem ter acessos diferenciados e controlar os espaços de contextualização, tais transformações de significados podem estar profundamente implicadas em comportamentos mais amplos de desigualdade social. De acordo com Erlich (2015), torna-se relevante examinar a forma com que as histórias originais podem estar sujeitas a alterações e modificações à medida que se deslocam para outras formas e contextos dentro do sistema legal. Bucholtz (2003) postula que é importante observar a inter-relação entre o oral e o escrito e entre as primeiras e as últimas versões do "mesmo" discurso oral ou escrito.

Ainda sob a luz da teoria das entextualizações, Erlich (2015) versa sobre a assimetria existente no discurso jurídico entre pessoas leigas e os representantes legais. Isso porque é fundamental lembrar que os processos legais são construídos com base em discursos orais proferidos por pessoas leigas, que se tornam rés ou não, e que tais discursos vão sendo (en) (re) (con)textualizados por profissionais especializados até o veredito final. Esta assimetria, de acordo com a autora, gera algumas consequências, pois nem todas as narrativas ou os gêneros/ estilos narrativos obtêm o mesmo valor e a mesma legitimação aos olhos da lei, assim como, as narrativas produzidas por pessoas leigas, frequentemente, não retêm seus significados originais conforme circulam dentro das instituições jurídicas.

Em outro estudo, Erlich (2007) mostra que a variedade de re-entextualizações do discurso legal potencializa a análise desse discurso visto que juízes diferentes podem apresentar diferentes pressuposições sobre as interpretações feitas de uma determinada fala. Ao investigar as formas com que as cortes narram e julgam casos de estupro, por exemplo, Erlich (2007) demonstra como os textos viajam pelos contextos por meio das diversas entextualizações e transformações feitas pelos profissionais envolvidos nos processos. Bloomaert (2005) chama essa metodologia de "trajetória textual". Wortham e Rhodes (2015) atestam que tais trajetórias envolvem mais que o contexto em nível macro e vão além do âmbito de tipos sociais de circulação ampla. Em vez disso, “elas se comportam como uma unidade de análise entre o 'macro' e o 'micro' - uma trajetória de eventos condicionados e relacionados que juntos cumprem uma função social" (WORTHAM; RHODES, 2015, p. 160).

Ainda sobre as trajetórias textuais, Bloomaert (2005) postula que existe um movimento do discurso através dos contextos, a fala é transformada em notas, resumos, boletins oficiais, citações, discussões e outros, como, por exemplo, nos contextos institucionais. Nem todo contexto é/está acessível a todos e as práticas de reentextualização dependem de quem tem acesso a qual espaço contextual. A dinâmica de entextualização claramente nos leva de volta a questões de acesso diferenciado aos recursos de poder e, portanto, nos leva diretamente à estrutura social (BAUMAN E BRIGGS, 1990). As entextualizações no contexto 
jurídico envolvem uma série de eventos desde a narrativa oral inicial registrada no Boletim de Ocorrência em uma delegacia de polícia, que é retextualizada e entextualizada por escrito por um profissional da área, passando pelos pareceres do Ministério Público e pelos textos redigidos pela defesa, até a sentença final. Tudo isso passa por enquadramentos legais, avaliações sobre o que é verdadeiro, até um relatório conclusivo, transformando a história muito além da "original".

De acordo com a perspectiva etnográfica, existe a consciência de que o discurso é contextualizado em cada fase da sua existência e que todo ato de produção, reprodução e consumo de discurso envolve mudanças contextuais. "Ao estudar o discurso e a estrutura social, esse movimento do discurso através dos contextos parece ser uma empreitada crítica crucial uma vez que contém importantes aspectos de poder" (BLOOMAERT, 2001, p. 110).

Assim, como diz Carranza (2010), a rede de papéis sociais e as relações específicas de poder precisam fazer parte da análise de trajetórias de histórias e textos na administração da justiça criminal. O processo de entextualização envolve mecanismos de relexicalização, explicitação e finalização dos enunciados produzidos pelo depoente. O discurso não mais pertencerá a ele.

A autora complementa seu pensamento dizendo que uma das descobertas de sua pesquisa é que, na prática do julgamento oral, são os textos escritos que são mais percebidos, representados e usados como veículos de verdade. A prevalência tradicional de textos escritos é mobilizada ao se considerar o texto como artefato que exibe assinaturas e perdura através do tempo.

Embora a doutrina jurídica e os profissionais da lei incorporem a importância da oralidade, a superioridade do texto escrito e a exaustividade com que é referenciado prevalecem. Cabe ressaltar aqui que as interações entre os réus e seus representantes podem ficar comprometidas devido às entextualizações feitas durante o processo pelos mais diversos profissionais envolvidos.

Além disso, Carranza (2010) corrobora a percepção de que a comunidade de fala compartilha a ideologia do texto fixo, ou seja, a ideia de que os autores são consistentemente capazes de produzir cópias de seus próprios textos sem variações consideráveis ou contradições, independentemente do contexto da situação e o co-participante concreto em cada interação particular. A superioridade do texto escrito é preservada. "Claramente, tal procedimento é institucionalmente compatível com o peso do processo que caracteriza a escrita em outras instâncias da lei” (CARRANZA, 2010, p. 179).

Desta forma, parece-nos estar clara a importância de se considerarem as situações e seus contextos para que se possa entender o texto jurídico escrito, levando em conta fatores de ordem social, interações face a face que venham a fazer parte do processo jurídico como um todo e as condições narrativas das histórias relatadas, já que irão afetar as 
sentenças proferidas por um juiz ou desembargador e que afetarão os indivíduos no futuro. Fazendo referência aos objetivos deste trabalho, buscamos analisar como as vidas das muIheres envolvidas no crime em questão são afetadas por serem percebidas de forma diversa por juízes diferentes ao concederem ou não a prisão domiciliar.

Na seção a seguir, apresentamos questões metodológicas e a contextualização da pesquisa em relação aos dados gerados.

\section{METODOLOGIA E CONTEXTUALIZAÇÃO}

Esta pesquisa tem cunho qualitativo e, segundo Denzin e Lincoln (2006), busca o estudo e o entendimento da vida humana, por meio do estudo do uso e da coleta de uma variedade de materiais empíricos que descrevem momentos rotineiros e problemáticos na vida dos indivíduos. A pesquisa qualitativa é um campo interdisciplinar e transdisciplinar que atravessa as humanidades e as ciências sociais por ter foco multiparadigmático.

Ainda de acordo com os autores, o pesquisador se torna um bricoleur, ${ }^{6}$ já que reúne peças que se encaixam de acordo com as especificidades e as complexidades da situação pesquisada. Essa bricolagem "é uma construção que sofre mudanças e assume novas formas à medida que se acrescentam diferentes instrumentos, métodos e técnicas de representação e de interpretação a esse quebra-cabeça" (DENZIN e LINCOLN, 2006, p.18). Isso porque é no decorrer da pesquisa, mais precisamente, no processo de geração e de análise de dados que o pesquisador verificará os métodos e abordagens a serem utilizados como, por exemplo, técnicas da etnometodologia, da hermenêutica, do construcionismo, das entrevistas, da psicanálise, entre outros, para a interpretação de seus dados.

Neste estudo, os significados do meio social de construção dos discursos serão analisados a partir de textos como elementos de eventos sociais. Segundo Fairclough (2000, p. 8), "textos podem suscitar mudanças em nossos conhecimentos (podemos aprender com eles) em nossas atitudes, em nossos valores e assim por diante". Os efeitos sociais do texto dependem do processo de construção de significados e o recurso de analisá-los contribui para entender este processo. Enfatiza-se, aqui, o processo de construção de significados sociais dos textos institucionais jurídicos que são o foco do trabalho, já que existem diversos autores envolvidos nas ações sociais em questão.

6 Termo usado por autores como Levi-Strauss, C. The Savage Mind. 2 ed. Chicago: Chicago University Press, 1966 apud Denzin e Lincoln, 2006. 


\subsection{CONTEXTO DA PESQUISA}

Os dados para este trabalho foram coletados de um processo judicial em que se observa o caso de duas mulheres infratoras grávidas envolvidas no mesmo delito, uma que não foi e outra que foi beneficiada pelo Artigo 318 do Decreto-Lei 3689/41 do Código de Processo Penal (CPP) que teve alterações em sua redação por meio da Lei $n^{\circ}$. 12357/2016, a qual dispõe acerca da formulação e da implementação de políticas públicas voltadas para as crianças que estão na "primeira infância". Além disso, esta Lei trouxe alterações no Estatuto da Criança e do Adolescente (NUNES, 2017). As modificações dos incisos IV e V do Artigo 318 têm como objetivo garantir à criança o convívio familiar.

Em 20 de fevereiro de 2018, a $2^{\text {a }}$ Turma do Supremo Tribunal Federal (STF), ao examinar e decidir o Habeas Corpus (HC) 143.641, impetrado pelo Coletivo de Advogados de Direitos Humanos (Cadhu) e pela Defensoria Pública da União, bem como pelo defensor públicogeral federal, resolveu estender a todas as mulheres infratoras grávidas ou com filhos menores de 12 anos o direito à prisão domiciliar em lugar da prisão cautelar. Em princípio, isso nos faz pensar que todas que se encontram nessa situação são beneficiadas pelo Habeas Corpus. Uma das rés em questão obteve o benefício da prisão domiciliar e outra não. A partir do inquérito, sabemos que uma delas já estava grávida quando participou do crime e este fato parece ter contribuído para um resultado positivo conforme veremos na análise dos dados.

O inquérito é a fase inicial de uma investigação que pode ou não se tornar um processo. Nesta primeira fase, há o Registro de Ocorrência (Termo Circunstanciado) ou o Auto de prisão em flagrante da autora do crime feitos na Delegacia de Polícia; Termos de Declaração de testemunhas (se houver); Exame de corpo de delito (se necessário) e Mandado de intimação à autora do crime caso não seja presa em flagrante.

A Promotoria de Investigação Penal apresenta denúncia contra a ré para que apresente sua defesa prévia, que pode ser feita pela Defensoria Pública ou por advogado particular. Na etapa seguinte, há os interrogatórios e a oitiva das testemunhas em audiência, tudo registrado em papel e gravado em mídia eletrônica. São feitas as Alegações finais do Promotor e da Defesa para que o juiz analise e dê a Sentença. Após a finalização do julgamento em primeira instância de um processo, o defensor do réu poderá entrar com recursos perante instância superior, segunda instância, TRFs ou tribunais superiores, a qual deverá analisar o processo e emitir sua decisão sobre o caso, o acórdão. Na $2^{a}$ Instância, o processo será analisado por um relator, geralmente um desembargador, o qual emitirá seu parecer sobre o caso, sendo que os demais membros do órgão colegiado poderão ou não seguir o parecer do relator.

Caso a ré esteja encarcerada, a prisão domiciliar pode ser requerida a qualquer momento durante o processo por meio de uma Petição. E tais pedidos e sentenças, juntamente com a documentação mencionada, constituem o foco deste trabalho. 
Cabe ressaltar que os processos são de domínio público e podem ser acessados pela internet no site do Tribunal de Justiça do Rio de Janeiro (www.tiri.jus.br), ou nas Varas Criminais, caso não tenham sido digitalizados. Poderá ser necessário o auxílio de um advogado para o caso de processos digitalizados, tendo em vista que alguns documentos são anexados ao processo em arquivos separados aos quais os advogados e defensores têm acesso. Ressaltamos que tal procedimento não compromete a condição pública de um processo, pois qualquer pessoa pode ter acesso aos autos nos fóruns ou depois que são arquivados.

O artigo 93, inciso IX, da Constituição Federal de 1988 corrobora tais argumentos, atestando que

IX todos os julgamentos dos órgãos do Poder Judiciário serão públicos, e fundamentadas todas as decisões, sob pena de nulidade, podendo a lei limitar a presença, em determinados atos, às próprias partes e a seus advogados, ou somente a estes, em casos nos quais a preservação do direito à intimidade do interessado no sigilo não prejudique o interesse público à informação; (Constituição Federal, Redação dada pela Emenda Constitucional n 45, de 2004)

\subsection{CONTEXTUALIZANDO O PROCESSO ANALISADO}

As duas mulheres infratoras, Dulce e Amanda, fizeram parte de um assalto a um ônibus circular junto com dois homens em Dezembro de 2017, na cidade do Rio de Janeiro. O ônibus foi interceptado e cercado por uma viatura da polícia militar e sendo auxiliado por outra equipe. Todos se renderam após uma breve negociação. Os acusados foram encaminhados para a Delegacia de Polícia, onde foram colhidos seus depoimentos, e permaneceram presos em flagrante. Posteriormente, foram encaminhados a outras instituições prisionais. Cada um deles teve sua defesa feita em momentos e circunstâncias diversas e os desdobramentos da prisão de Amanda e Dulce são o foco desta pesquisa.

As duas mulheres foram ouvidas, fizeram Exame de Corpo de Delito e foi constatada a gravidez de Dulce. A partir daí, a Defensoria Pública, dentro dos trâmites legais, fez a primeira solicitação da prisão domiciliar de Dulce e, em outro momento, o Habeas Corpus e obteve sucesso. A primeira tentativa foi em vão.

Amanda, por sua vez, teve a gravidez confirmada apenas quando estava na prisão. Não há documentos que comprovem a gravidez na data do crime. A Defensoria solicitou a prisão domiciliar em mais de um momento, mas sem sucesso. O Habeas Corpus que faz parte dos dados desta pesquisa foi impetrado no nono mês de gravidez de Amanda. Foi expedido um Acórdão, já que o processo precisou ser analisado por uma instância superior tendo em vista a decisão desfavorável à prisão domiciliar da ré.

Ressaltamos aqui que os defensores das duas rés tomaram como base as leis citadas anteriormente: o Artigo 318 do CPP, o HC 143.641/SP julgado pelo STF e as Regras de Bangkok, como veremos na análise de dados. Contudo, os entendimentos dos julgadores se mostram divergentes, mesmo se tratando de assuntos comuns, isto é, a prisão domiciliar que pode ser concedida a mulheres grávidas como pena alternativa à prisão preventiva e 
o mesmo delito cometido por ambas. Observamos nas entextualizações e transformações do texto que as interpretações se mostram diferentes, principalmente, no que diz respeito ao problema gestação.

\section{UM CASO, DUAS MEDIDAS}

Alguns trechos de documentos que compõem o processo de Dulce e Amanda foram selecionados a fim de se buscar entendimento a respeito da escrita e reescrita dos textos pelos profissionais envolvidos, bem como a forma com que a legislação é usada como fundamentação e entextualizada em casos como esses. Não esperamos aqui dar conta de todos os aspectos discursivos envolvidos na feitura dos textos, portanto escolhemos trechos que nos parecem ser mais relevantes de acordo com as propostas teórica e metodológica.

\subsection{DULCE}

Vimos anteriormente que Dulce estava grávida quando participou do assalto ao ônibus. Podemos perceber que isso não é uma condição para que a pena não seja imputada à mulher, mas pode ser um atenuante, tendo em vista a legislação vigente que ampara as mulheres infratoras gestantes e/ou com filhos menores e as condições de encarceramento observadas no Brasil. As Regras de Bangkok vêm corroborar a necessidade de penas alternativas para as mulheres infratoras, pois esta população carcerária tem aumentado nos últimos anos.

Conforme notamos no trecho a seguir, o defensor entextualiza a prisão preventiva da ré, que ficou 4 meses presa até que a prisão domiciliar fosse decretada. A gravidez não se configurou como atenuante desde o início do processo, por isso, a necessidade do $\mathrm{HC}$ requerendo o benefício da prisão domiciliar e anexando ao processo a documentação comprobatória da gravidez, sendo que isso já havia sido registrado quando do exame de corpo de delito. Há uma crítica ao juiz que proferiu tal decisão pelo fato de não ter considerado a gravidez e tampouco "prova de que a ré estaria grávida".

\footnotetext{
Em audiência de custódia, foi decretada a prisão preventiva da acusada, apesar de gestante, pois, para o magistrado, o fato de ela ser primária e possuir residência certa não constituiria, por si só, elemento suficiente para concessão da liberdade provisória (fl. 112).

Com base na pena do crime em abstrato, considerou ainda que outras medidas cautelares não seriam suficientes, proporcionais e adequadas. Aduziu ainda que não haver prova de que a ré estaria grávida e que poderia ter acompanhamento médico no cárcere (fl. 111/112).
}

Percebe-se também que há referências ao "acompanhamento médico no cárcere", mas tal contextualização não se mostra passível de ser acatada tendo em vista as condições precárias de encarceramento observada no país e que são comentadas tanto no HC 
de Dulce como na decisão do HC 143641/SP expedido pelo STF concedendo a prisão domiciliar a mulheres que se encaixem no que dispõe o Artigo 318 do CPP. A relevância, aqui, reside em demonstrar como as instâncias superiores de justiça reconhecem a necessidade de tratamento especial para os casos de mulheres encarceradas e seus filhos, mas isso não parece ser levado em conta pelos julgadores.

Como reconhecido pelo Supremo Tribunal Federal no julgamento do HC 143641/SP, o Estado não tem condições mínimas de garantir os cuidados à maternidade, até mesmo das mulheres que não estão em situação prisional, [...] (grifos mantidos do original)

A defensoria continua suas fundamentações trazendo questões narrativas a respeito do trato para com a mulher e para com os filhos mencionando a Constituição Federal e as Regras de Bangkok. Observa-se a entextualização não somente das Regras de Bangkok, mas também com outros documentos legais da mesma seara, contextualizando-os com a legislação brasileira.

\begin{abstract}
Tal como constante da ementa da decisão, os cuidados com a mulher presa se direcionam não apenas a ela, mas igualmente aos seus filhos, os quais sofrem injustamente as consequências da prisão, em flagrante contrariedade ao art.227 da Constituição, cujo teor determina que se dê prioridade absoluta à concretização dos direitos destes.

Incide o amplo regramento internacional relativo a Direitos Humanos, em especial das Regras de Bangkok, segundo as quais deve ser priorizada solução judicial que facilite a utilização de alternativas penais ao encarceramento, principalmente para as hipóteses em que ainda não haja decisão condenatória transitada em julgado. (grifos mantidos do original)
\end{abstract}

A juíza responsável pelo julgamento de Dulce acatou o pedido e concedeu a prisão domiciliar fazendo referência aos documentos também utilizados pela defensoria, entextualizando-os de forma a considerar que o benefício possa ser estendido a "todas as mulheres presas, gestantes, puérperas, ou mães de crianças e deficientes sob sua guarda, excetuados os casos de crimes praticados por elas mediante grave violência ou grave ameaça, contra seus dependentes [...]". Há referência ainda ao Artigo 319 do CPP que versa sobre medidas cautelares diversas da prisão, já que a acusada precisará cumprir determinadas exigências judiciais enquanto estiver sob regime de prisão domiciliar.

\footnotetext{
Considerando a decisão proferida pelo E. Supremo Tribunal Federal nos autos do HC 143641/SP, no sentido de conceder a ordem para determinar a substituição da prisão preventiva pela domiciliar - sem prejuízo da aplicação concomitante das medidas alternativas previstas no artigo 319 do CPP - de todas as mulheres presas, gestantes, puérperas, ou mães de crianças e deficientes sob sua guarda, excetuados os casos de crimes praticados por elas mediante grave violência ou grave ameaça, contra seus dependentes ou, ainda, em situações excepcionalíssimas e, estando a denunciada DULCE, grávida de cerca de 20 semanas (fl. 167), a despeito da gravidade dos fatos narrados na denúncia, SUBSTITUO A PRISÃO PREVENTIVA PELA DOMICILIAR, sem prejuízo de aplicar a medida cautelar de comparecimento a todos os atos do processo para os quais for intimada (grifos mantidos do original).
}

Conforme observamos no caso de Dulce, a trajetória dos textos do processo culminou em um resultado satisfatório "SUBSTITUO A PRISÃO PREVENTIVA PELA DOMICILIAR, sem prejuízo de aplicar a medida cautelar de comparecimento a todos os atos do processo para 
os quais for intimada". Os olhares macrossociais que envolvem aspectos relativos a mulheres infratoras, gravidez e filhos foram levados em conta na situação específica do contexto microssocial da ré em questão. Mas isso não é o que se observa no caso a seguir.

\subsection{AMANDA}

Amanda não estava grávida na ocasião do assalto. Assim como aconteceu com Dulce, a prisão em flagrante foi convertida em prisão preventiva devido à gravidade do delito conforme registram outros documentos que compõem o processo. O pedido de prisão domiciliar foi feito em duas circunstâncias e foi negado nas duas. Embora visivelmente grávida, ainda assim os julgadores envolvidos no caso não se manifestaram a favor da prisão domiciliar e analisaremos trechos do pedido de Habeas Corpus e do Acórdão expedido por uma desembargadora. Mesmo estando grávida na Audiência de Custódia, a prisão preventiva foi aplicada "negando-lhe qualquer medida cautelar diversa da prisão e/ou a imposição de prisão domiciliar".

\footnotetext{
Outrossim, levada à presença da autoridade judiciária em audiência de custódia, apesar de sua situação de gravidez perceptível aos olhos, além de confirmada pela ora paciente, aquele juízo converteu a prisão em flagrante em prisão preventiva, negando-lhe qualquer medida cautelar diversa da prisão e/ou a imposição de prisão domiciliar.
}

Observamos aqui a entextualização por meio de relexicalização e de finalização dos enunciados da depoente "além de confirmada pela ora paciente", que passam a não mais pertencer-Ihe (CARRANZA, 2010). A voz da paciente em questão se faz presente por meio do discurso de seu defensor "levada à presença da autoridade judiciária em audiência de custódia”. Ele dá continuidade às suas argumentações e traz uma citação da decisão judicial em primeira instância a respeito da prisão. Observa-se que o juiz em questão retextualiza o crime como "delito(s) praticado(s) mediante grave ameaça em concurso de agentes" para fundamentar a decisão sobre a prisão preventiva da acusada e completa que não há "provas" da gravidez, mas se forem necessários cuidados médicos, ela os terá no cárcere. Ora, se não houvesse gravidez, por que seriam mencionados os cuidados médicos?

Veja que quando da negativa daquele juízo quanto a concessão da prisão albergue domiciliar e/ou a aplicação de medidas cautelares desencarceradoras, assim fundamentou:

"(..) Há que se ressaltar que se trata de delito(s) praticado(s) mediante grave ameaça em concurso de agentes Entendo que, no caso concreto, se encontram presentes os requisitos autorizadores da prisão preventiva, previstos no artigo 312, do CPP, notadamente, a garantia da ordem pública, diante da gravidade de 04 (quatro) anos de reclusão, previsto no artigo 313, inciso 1, do Código de Processo Penal, não se mostrando as medidas cautelares diversas da prisão suficientes, proporcionais e adequadas à prevenção e repressão do(s) crimes(s), razão pela qual são inaplicáveis ao caso em análise, não sendo passível a concessão de prisão domiciliar por ausência de prova, sendo certo que eventual acompanhamento médico poderá ser dispensado mesmo no cárcere (grifos mantidos no original). 
As argumentações e fundamentações do defensor se baseiam, além das leis e de jurisprudências ${ }^{7}$ semelhantes, na entextualização da decisão judicial anterior. Nota-se que o juiz diz que estão "presentes os requisitos autorizadores da prisão preventiva", mas desconsidera a concessão da domiciliar. Como podemos observar, há diversas incongruências entre a decisão e a situação social real de Amanda. No trecho a seguir, percebemos alguns desvios, já que o mesmo juiz disse, no mesmo documento, conforme apresentamos acima, que não havia provas que que a ré estivesse grávida no dia do assalto.

Destarte, distribuídos os autos à autoridade apontada como coatora, a defesa técnica novamente postulou em sede de audiência a conversão da prisão preventiva da Paciente Amanda em prisão domiciliar nos termos do artigo 318, IV, do Código de Processo Penal, o que restou indeferido nos seguintes termos:

[...] Estamos diante de uma situação excepcional em que a manutenção da prisão preventiva se justifica, até mesmo porque por ocasião do delito, a ré já se encontrava gestante, devia ter levado em conta o sev estado naquele momento e não agora para pretender se livrar da aplicação da lei penal. Dessa forma, indefiro o pedido formulado pela defesa (grifos mantidos do original).

Percebemos ainda, nas palavras do juiz, que ele apresenta justificativas para manter a prisão preventiva no fato de a ré já estar grávida e não "ter levado em conta seu estado naquele momento" e "pretender se livrar da aplicação da lei penal”. Parece-nos um julgamento pessoal sobre a gestante usar seu estado a fim de cometer um crime e não ser punida pela lei. Apesar de reconhecer o evidente enquadramento da situação da paciente no Artigo 318, inciso V do Código de Processo Penal, o juiz fundamenta o indeferimento do pleito defensivo em ponderações que dizem respeito apenas à chamada gravidade do delito e sua repercussão e que as medidas cautelares da prisão são "suficientes, proporcionais e adequadas à prevenção e repressão do(s) crimes(s)". Distancia-se, assim, do objetivo maior da previsão legal e aplicação da prisão domiciliar à gestante.

O defensor dá continuidade ao seu texto sempre com base na legislação vigente citando o Artigo 318 do CPP, o Artigo 5 . da Constituição Federal, o HC 143641/SP e as Regras de Bangkok. Isso porque ele também apresenta argumentações desfavoráveis ao encarceramento de gestantes devido às condições precárias observadas nas prisões brasileiras, mais especificamente no Estado do Rio de Janeiro, condições estas que são mencionadas tanto na Constituição como nas Regras de Bangkok.

\footnotetext{
Aprisionar gestantes em condições indignas e desumanas tal qual se tem observado no Estado do Rio de Janeiro representa, sem dúvida alguma, violação da dignidade humana, da vida, da integridade psicofísica e do direito a não ser submetido a tratamento cruel, desumano ou degradante, em violação frontal do disposto na Constituição Cidadã de 1988.
}

\footnotetext{
7 A jurisprudência é uma fonte formal do direito brasileiro, a qual trata da forma como o a universo jurídico se exterioriza. São decisões judiciais emitidas pelos tribunais, as quais viram fonte de consulta para decisões futuras.
} 
Há também a preocupação com o nascituro, já que existem leis que o protegem e cuidam de seus direitos à liberdade. A criança tem o direito de nascer em liberdade e a não permanecer no cárcere. O pedido de prisão domiciliar configurou-se como urgente, haja vista que Amanda estava no nono mês de gravidez e a logística para o parto em condições adequadas de transporte e encaminhamento hospitalar da gestante são quase sempre insalubres, impróprias e, por tudo isso, arriscadas.

Contudo, Amanda teve a prisão domiciliar indeferida. A desembargadora responsável pelo pleito entendeu que a prisão domiciliar não era cabível. Ao iniciar o texto do Acórdão, o faz em termos sucintos e resumidos do caso em questão.

Habeas Corpus. Paciente condenada pela prática do delito [...] Gravidez. Pleito de concessão de prisão domiciliar, na forma descrita no artigo 318, IV, do Código de Processo Penal. Conversão em prisão domiciliar que não é automática, devendo ser analisadas as circunstâncias do delito praticado. De acordo com a denúncia os crimes praticados pela paciente são gravíssimos, eis que foram cometidos dentro de um coletivo, mediante o emprego de duas granadas, em concurso de agentes, além do fato de a paciente ser reincidente específica em crimes contra o patrimônio. Ré que se encontra custodiada em Unidade Materno Infantil. Impetrante que não comprovou qualquer descaso ou omissão do Sistema Penitenciário ou risco à gravidez. Sendo desnecessária, no momento, a prisão domiciliar. Constrangimento não verificado. Ordem denegada.

A forma breve com que o crime é reescrito denota que a julgadora comenta a existência do direito à prisão domiciliar, mas sem analisá-lo, já que diz apenas que devem "ser analisadas as circunstâncias do delito praticado", enfatiza a gravidade do delito, comenta que a ré está custodiada em uma unidade materno-infantil provedora de cuidados à mãe e, portanto, julga desnecessária a prisão domiciliar.

No texto do Relatório, que compõe o Acórdão, a entextualização do crime, a denegação da prisão domiciliar e as fundamentações são feitas resumidamente. $\mathrm{O}$ crime é retextualizado apenas fazendo referência à legislação vigente.

Depreende-se das informações prestadas pela autoridade dita coatora, que a paciente foi denunciada, juntamente com outros dois corréus, pela prática dos delitos descritos no artigo 157 , §2 $2^{\circ}$, inciso Il, do Código Penal (três vezes na forma do artigo 70 do CP) e no artigo 16, parágrafo único, inciso III, da Lei n. ${ }^{\circ} 10.826 / 03$ e no artigo 244-B, da Lei n. ${ }^{\circ} 8.069 / 90$, na forma do artigo 69 do Código Penal.

O artigo 318 do CPP é apenas citado como forma de reconhecimento de sua existência. Ao mencionar o HC 143641/SP, a relatora faz as seguintes considerações

Todavia, tal julgamento [do HC 134641/SP] elencou três exceções para a concessão da prisão domiciliar, quais sejam: crimes praticados por elas mediante violência ou grave ameaça, contra seus descendentes ou, ainda, em situações excepcionalíssimas, as quais deverão ser devidamente fundamentadas pelos juízes que denegarem o benefício, como ocorreu na hipótese dos autos.

Ademais, deve-se lembrar que o delito a que responde a paciente é gravíssimo, eis que de acordo com a denúncia os delitos foram cometidos dentro de um coletivo, mediante o emprego de duas granadas, em concurso de agentes, além do fato de a paciente ser reincidente específica em crimes contra o patrimônio. De modo que em liberdade a paciente coloca em risco à ordem pública, como bem salientado pela autoridade apontada como coatora. 
Mais uma vez, entextualiza o crime como "gravíssimo", sem considerar quaisquer possibilidades de cumprimento da pena de modo alternativo, já que uma criança está prestes a nascer e, como postulou o defensor, há leis que protegem o menor. A preocupação maior continua sendo a gravidade do delito sem ao menos serem consideradas quaisquer possibilidades de se conceder a prisão domiciliar já que a desembargadora postula que as situações excepcionais "deverão ser devidamente fundamentadas pelos juízes que denegarem o benefício, como ocorreu na hipótese dos autos". Isso nos parece uma forma de se dizer que nada mais há de ser feito, já que os autos do processo registram os fatos. Parece não haver preocupações com quaisquer mudanças na situação social, pois o texto da desembargadora apresenta-nos o caso de Amanda sem variações consideráveis, independentemente do contexto da situação e dos co-participantes concretos nessa interação particular.

Ela termina o texto do relatório da seguinte forma Deste modo, não se verifica a ocorrência de qualquer constrangimento ilegal, eis que a paciente
se encontra acautelada em Unidade Materno Infantil, mostrando-se desnecessária a prisão do-
miciliar neste momento.

Chamamos a atenção para o uso do da unidade lexical "desnecessária", configurando um julgamento em torno das narrativas construídas pelos juízes anteriores a respeito do caso como um todo, enfatizando o crime e desconsiderando a gestante e seu filho. Nota-se, ainda, que a paciente representa um risco à sociedade se colocada em liberdade, "como bem salientado pela autoridade apontada como coatora". As entextualizações são feitas com base nos textos escritos que compõem os autos do processo, sem considerarem os contextos macrossociais a respeito da prisão domiciliar (número de muIheres encarceradas, condições precárias das prisões brasileiras, saúde da mulher, liberdade da criança, relação mãe e filho na primeira infância, dentre outros) e os aspectos microssociais em relação à Amanda e todo o contexto envolvendo sua gestação e a criança que estava para nascer.

\section{CONSIDERAÇÕES FINAIS}

Ao proceder a análise dos dois casos, parece clara a diferença entre os desdobramentos dos dois casos. Dulce, mesmo tendo cometido o mesmo crime que Amanda, foi beneficiada com a prisão domiciliar como pena alternativa à prisão preventiva nos moldes da lei. É uma forma de penalidade visto que a mulher infratora precisa cumprir algumas exigências legais para que possa permanecer em seu domicílio, como, por exemplo, ter endereço fixo e comparecer em juízo de acordo com o prazo e condições fixadas pelo juiz a fim de informar 
e justificar suas atividades, conforme versa o Artigo 319 do CPP. Frisa-se que é uma decisão legal e fundamentada para que haja maior contato entre mãe e filho na primeira infância, mas parece ser considerada uma forma de fuga da aplicação da lei penal, como dito por um dos juízes do caso de Amanda.

A diferença entre os julgamentos aplicados parece residir na decisão e na presunção de culpabilidade sem demonstrar considerações sobre os contextos sociais existentes e claramente demonstrados nos casos e na legislação vigente. Os textos escritos, no caso de Amanda, demonstram certa superioridade ao que é demonstrado no decorrer do processo em relação à especificidade da situação social da ré devido à gravidez e às condições prisionais. A necessidade de prisão domiciliar é reduzida ao crime, à forma como ele é entextualizado e à gravidade do delito.

Parece-nos que considerar desnecessário o cumprimento da pena domiciliar e tomar como base o crime em si torna-se mais simples do que fundamentar adequadamente o motivo da não concessão. Por outro lado, apresentar justificativas e argumentações para as situações excepcionais que "deverão ser devidamente fundamentadas pelos juízes que denegarem o benefício" pode vir a ser algo complexo tendo em vista as leis existentes que salvaguardam as mulheres infratoras grávidas ou com filhos menores de 12 anos.

Assim, a entextualização como abordagem de observação dos textos escritos, contribui para a análise dos pedidos e decisões proferidas na justiça criminal. Vimos que, nos dois casos, os textos foram escritos e reescritos, retextualizados, contextualizados e recontextualizados tomando como base o mesmo crime. Todavia, as interpretações e as transformações aplicadas pelos julgadores mostraram-se distintas e tiveram desdobramentos divergentes. Os profissionais exerceram seus papéis, construíram suas narrativas e fundamentações dentro de um contexto macrossocial. Parece-nos que o contexto microssocial de Dulce foi levado em conta, mas Amanda não teve a mesma sorte. Se é que podemos chamar isso de sorte.

\section{AGRADECIMENTOS}

Agradeço à Coordenação de Aperfeiçoamento de Pessoal de Ensino Superior - CAPES pelo incentivo a esta pesquisa por meio da bolsa concedida para financiamento do curso de doutorado (Código de Financiamento 001) 


\section{REFERÊNCIAS}

ANDRUS, Jennifer. Beyond texts in contexts: Recontextualization and the co-production of texts and contexts in the legal discourse, excited utterance exception to hearsay. Discourse and Society, vol. 22(2), p. 115-136, 2011.

AUSTIN, John L. Quando dizer é fazer. Tradução. Porto Alegre: Artes Médicas, 1990.

BAHKTIN, Mikhail M. Os gêneros do discurso. In: Estética da criação verbal. São Paulo: Martins Fontes, 2003.

BASTOS, Liliana C. Diante do sofrimento do outro - narrativas de profissionais de saúde em reuniões de trabalho. Calidoscópio. Vol. 6, no. 2, p. 76-85, 2008.

Contando estórias em contextos espontâneos e institucionais - uma introdução ao estudo da narrativa. Calidoscópio. Vol. 3, no. 2, p. 74-87, 2005.

Narrativa e vida cotidiana. Scripta. Vol. 7, no. 14, p. 118-127, 2004.

BASTOS, Liliana C. e BIAR, Liana A. Análise de narrativa e práticas de entendimento da vida social. DELTA. Vol. 31, no. Spe, 2015.

BAUMAN, Richard; BRIGGS, Charles. Poética e performance como perspectivas críticas sobre a linguagem e a vida social. Annual Review of Anthropology, v. 19, p. 59-88, 1990. (Tradução)

BLOOM, Jan P. e GUMPERZ, John J. O significado social na estrutura linguística - Alternância de códigos na Noruega. In: RIBEIRO, Branca T. e GARCEZ, Pedro M. (orgs). Sociolinguística Interacional. São Paulo: Edições Loyola, 2002 [1972].

BLOOMAERT, Jan. Contexto é/ como crítica. Critique of Antrophology. Vol 21[1] p. 13-32, 2001.

BLOOMAERT, Jan. Discourse - A Critical Introduction. Cambridge: Cambridge University Press, 2005.

BRIGGS, Charles. Anthropology, Interviewing, and Communicability in Contemporary Society. Current Anthropology, Vol. 48, No. 4, 2007.

CARRANZA, Izolda E. Truth and Autorship in Textual Trajectories. Telling Stories: Language, Narrative and Social Life. In: SCHIFFRIN, Debora, DE FINA, Anna \& NYLUND, Anastasia. Telling stories: Language, Narrative and Social Life. Washington: Georgetown University Press, 2010.

CONSELHO NACIONAL DE JUSTIÇA. Regras de Bangkok - Regras das Nações Unidas para o tratamento de mulheres presas e medidas não privativas de liberdade para mulheres infratoras. Conselho Nacional de Justiça, Departamento de Monitoramento e Fiscalização do Sistema Carcerário e do Sistema de Execução de Medidas Socioeducativas, Conselho Nacional de Justiça - 1. Ed - Brasília: Conselho Nacional de Justiça, 2016. Disponível em:

http://www.cnj.jus.br/files/conteudo/arquivo/2016/03/a858777191da58180724ad5caafa6086.pdf Acesso em: $10 / 09 / 2017$.

DE FINA, Anna e GEORGAKOPOULOU, Alexandra. Analysing narratives as practices. Qualitative Resarch (SAGE Publications) Vol. 8, No. 3, p. 379-387, 2008.

DENZIN, Norman K. e LINCOLN, Yvonna. S. A disciplina e a prática da pesquisa qualitativa. In: DENZIN, Norman K.; LINCOLN, Yvonna S. O planejamento da pesquisa qualitativa: teorias e abordagens. Porto Alegre: Artmed, 2006. p. 15-42.

DICIONÁRIO DIREITO. Disponível em https://dicionariodireito.com.br/. Acesso em 14/07/2018.

ERLICH, Susan. Narrative, Institutional Processes and Gendered Inequalities. In: DE FINA, Anna. and GEORGAKOPOLOU, Alexandra. The Handbook of Narrative Analysis. Sussex: John Wiley \& Sons Inc, 2015

ERLICH, Susan Legal discourse and the cultural intelligiblity of gendered meanings. Journal of Sociolinguistics 11/4, p. 452-477, 2007.

FAIRCLOUGH, Norman. Analysing Discourse - Textual Analysis for Social Research. New York: Routledge, 2003. 
FAIRCLOUGH, Norman. Discurso e Mudança Social. Brasília: Editora UnB, 2001.

FREEMAN, Mark. Narrative as a Mode of Understanding - Method, Theory, Praxis. In: De Fina, Anna. and Georgakopolou, Alexandra. The Handbook of Narrative Analysis. Sussex: John Wiley \& Sons Inc, 2015

G1. Rio de Janeiro. STJ concede liminar que garante prisão domiciliar a Adriana Ancelmo. Disponível em http://g1.globo.com/rio-de-janeiro/noticia/sti-concede-prisao-domiciliar-a-adriana-ancelmo-dizadvogado.ghtml publicado em 24/03/2017, acesso em 02/09/2017.

GEE, James P. An Introduction to Discourse Analysis - Theory and Method. $2^{\text {nd }}$ Ed. London: Routledge, 2005.

GOFFMAN, Erving. A situação negligenciada. In: RIBEIRO, Branca T. e GARCEZ, Pedro M. (Orgs). Sociolinguística Interacional. São Paulo: Edições Loyola, 2002 [1964].

KOCH, Ingedore V. A inter-ação pela linguagem. São Paulo: Contexto, 2003

LABOV, William. The transformation of experience in narrative syntax. In: Language in the Inner City. Philadelphia: U. of the Pennsylvania Press, 1972.

MARCUSCHI, Luiz A. Da fala para a escrita - atividades de retextualização. 5a . ed. São Paulo: Cortez, 2004.

MOITA LOPES, Luiz Paulo da. Pesquisa interpretativista em linguística aplicada: a linguagem como condição e solução. DELTA. Vol 10, No. 2, p. 329-338, 1994

MOITA LOPES, Luiz Paulo da. Uma Linguística Aplicada mestiça e ideológica: interrogando o campo como Linguista Aplicado. In: MOITA LOPES, Luiz Paulo (Org.) Por uma Linguística Aplicada INdisciplinar. São Paulo: Parábola Editorial, 2006.

NEITSCH, Joana. Prisão domiciliar de mulher de Cabral chama atenção para direito de mães detentas. Gazeta do Povo. Disponível em http://www.gazetadopovo.com.br/vida-publica/justica-e-direito/prisaodomiciliar-de-mulher-de-cabral-chama-atencao-para-direito-de-maes-detentasacvcaom6wflh9o8hx68xm9rfo em 28/03/2107. Acesso em 02/09/2017.

NUNES, Helom. A Lei N.12357/2016 e o Processo Penal. Disponível em https://helomnunes.com/2016/03/13/alei-n-123572016-e-o-processo-penal/ Acesso em 02/09/2017.

PRESIDÊNCIA DA REPÚBLICA. Casa Civil. Constituição da República Federativa do Brasil de 1988. Disponível em https://www.jusbrasil.com.br/topicos/1699445/inciso-ix-do-artigo-93-da-constituicao-federal-de-1988. Acesso em 15/07/2018

PRESIDÊNCIA DA REPÚBLICA. Casa Civil. Decreto Lei 3689 de 3 de outubro de 1941. Disponível em http://www.planalto.gov.br/ccivil_03/decreto-lei/Del3689.htm_Acesso em 02/09/17.

PRESIDÊNCIA DA REPÚBLICA. Casa Civil. Lei no. 13.257, de 08 de março de 2016. Disponível em: http://www.planalto.gov.br/ccivil_03/_ato2015-2018/2016/lei/l13257.htm. Acesso em: 10/09/2017.

SARANGI, Srikant. Rethinking recontextualization in professional discourse studies. In: SARANGI, Srikant e WILSON, John. (eds). Text: an interdisciplinary journal for the study of discourse. Vol 18-2, 1998.

SILVA, Daniel. O texto entre a entextualização e a etnografia: um programa jornalístico sobre belezas subalternas e suas múltiplas recontextualizações. Linguagem em (Dis)curso - LemD, Tubarão, SC, v. 14, n. 1, p. 67-84, jan./abr. 2014.

SUPREMO TRIBUNAL FEDERAL. Habeas Corpus 143.641 São Paulo. Disponível em http://www.stf.jus.br/arquivo/cms/noticiaNoticiaStf/anexo/HC143641final3pdf/Voto.pdf Acesso em $14 / 06 / 2018$

WORTHAM, Stanton \& RHODES, Catherine R. Narratives across speech events. In: DE FINA, Anna and GEORGAKOPOLOU, Alexandra. The Handbook of Narrative Analysis. Sussex: John Wiley \& Sons Inc, 2015. 